\title{
Absorption of Calcium Measured by Intubation and Perfusion of the Intact Human Small Intestine
}

\author{
Ronald H. Wensel, Clayton Rich, Arthur C. Brown, and \\ WADE VOLWILER \\ From the Departments of Medicine and Physiology and Biophysics, University \\ of Washington School of Medicine and the Radioisotope Service, Veterans \\ Administration Hospital, Seattle, Washington 98105
}

A B S T R A C T Absorption of calcium was measured by direct intubation and perfusion of the small intestine in 10 volunteer normal adult subjects, two adults with celiac-sprue, and one with a parathyroid adenoma. A total of 60 studies were completed using one of two different levels, duodenojejunum or ileum. Solutions containing stable calcium, radiocalcium ${ }^{47}$, and a nonabsorbable dilution-concentration marker, polyethylene glycol, were infused at a uniform rate via the proximal lumen of a triple-lumen polyvinyl tube. The mixed intraluminal contents were continuously sampled by siphonage from two distal sites, 10 and $60 \mathrm{~cm}$ below the point of infusion. Unidirectional flux rates, lumen to blood and blood to lumen, and net absorption of calcium for the $50 \mathrm{~cm} \mathrm{seg-}$ ment of small intestine between the two collection sites were calculated from the measured changes in concentration of stable calcium, calcium-47, and polyethylene glycol.

Flux of calcium from lumen to blood in the duodenojejunum of normal subjects was appreciable even when the concentration of calcium in the perfusate was below that of extracellular fluid and, as the intraluminal concentration of calcium was increased through a range of 0.5 $3.5 \mu \mathrm{moles} / \mathrm{ml}$, was positively correlated, ranging from 1.9 to $7.0 \mu \mathrm{moles} / \mathrm{min}$ per $50 \mathrm{~cm}$. Repeated studies of individual subjects demonstrated a consistent pattern of absorptive efficiency in each, but significant variability from person to person. Flux from lumen to blood in the ileal segment occurred at a much lower rate than that found in the proximal intestine, and there was not a significant dependence upon intraluminal calcium concentra-

Dr. Wensel was a Postdoctoral Research Trainee in Gastroenterology, National Institute of Arthritis and Metabolic Diseases, Grant 2A-5099. His present address is Department of Medicine, University of Alberta, Edmonton, Alberta, Canada.

Received for publication 8 December 1967 and in revised form 2 March 1969. tion. The opposite flux, from blood to lumen, was low both in the duodenojejunum and ileum (average 0.76 $\mu$ moles $/ \mathrm{min}$ per $50 \mathrm{~cm}$ ) and was independent of the intraluminal calcium concentration. Unidirectional flux, lumen to blood, from the duodenojejunum was not altered by parathyroid extract administered at the time of the infusion, but was accelerated in the subject with a parathyroid adenoma and markedly reduced in the two subjects with celiac-sprue.

\section{INTRODUCTION}

Intestinal absorption of calcium has been studied extensively in small animals using perfused or ligated gut segments in vivo or in vitro. Investigators using these preparations have shown that transfer of calcium from mucosal to serosal surfaces of proximal small intestinal segments significantly exceeds that from distal segments and that the reverse movement of calcium is slight at all levels (1-4). In man, absorption of calcium has usually been studied only indirectly by means of balance measurements and by single or double isotope techniques (5-8), and little has been discovered about the relative rates of absorption at different levels of human intestine.

The studies herein reported examine the small intestinal transmucosal exchange of calcium in normal adult humans by measuring simultaneously the absorption of calcium, radioactive calcium, and water in relation to the concentration of calcium within the intestinal lumen at specific anatomic regions (upper vs. lower small intestine). Portions of this work have been summarized in very preliminary reports $(9,10)$. These experiments were conducted by intraluminal perfusion, employing a 3-channel catheter and polyethylene glycol as a concentration-dilution monitor.

Our observations demonstrate that calcium absorption is relatively reproducible under standard conditions at 
different times in a given subject, but that it varies from person to person and is greater in the proximal small intestine than in the ileum.

\section{METHODS}

Experimental design and calculations. The general method employed was a modification of that described by Cooper, Levitan, Fordtran, and Ingelfinger (11). The limitations and assumptions of this technique have been reviewed by Ford$\operatorname{tran}(12)$. Lumens were $1.7 \mathrm{~mm}$ I.D. Siphonage sites were of four closely approximated, spirally arranged openings. The tube assembly was led by a small mercury-filled rubber bag. A known mixture of calcium gluconate, ${ }^{47} \mathrm{Ca}$, and polyethylene glycol (PEG) in buffered isotonic saline was introduced at a constant rate into the intestinal lumen through the channel with the most proximal openings (infusion tube). Fluid was siphoned from the intestinal lumen for analysis through the next most distal tube openings, 10 $\mathrm{cm}$ beyond (proximal sampling site), and the most distal tube openings, $50 \mathrm{~cm}$ further (distal sampling site). The region between the infusion and proximal sampling sites was termed the mixing segment, and the region between the proximal and distal sampling sites was termed the test segment.

Since the intestinal epithelium is impermeable to PEG, the intraluminal fluid volume could be calculated from changes in PEG concentration, allowance being made for solution withdrawn via the sampling tubes. Net calcium absorption within the test segment is the difference between the amount of calcium entering and leaving the segment. We have used formulas which are analogous to those of Krawitt and Schedl (3) for calculation of net calcium absorption $\left(\dot{\mathrm{C}}_{\mathbf{a b s}}\right)$, flux of calcium from lumen to blood $\left(\dot{\mathrm{C}} \mathrm{a}_{\mathrm{lb}}\right)$ and flux from blood to lumen $\left(\dot{\mathrm{C}} \mathrm{a}_{\mathrm{bl}}\right)$, as follows:

$$
\begin{aligned}
& Q_{\text {in }}=\left(Q_{i} / P G_{p}\right)-Q_{p} \text { and } Q_{\text {out }}=Q_{\text {in }}\left(P E G_{p} / P G_{d}\right) \\
& \dot{\mathrm{C}}{ }_{\mathrm{a}}{ }_{\mathrm{abs}}=\dot{\mathrm{C}} \mathrm{a}_{\mathrm{p}}{ }^{*} Q_{\mathrm{in}}-\dot{\mathrm{C}} \mathrm{a}_{\mathrm{d}}{ }^{*} \mathrm{Q}_{\text {out }} \\
& \dot{C}_{a_{a b s}}=C a_{p} Q_{\text {in }}-C a_{d} Q_{\text {out }} \\
& \dot{\mathrm{C}} \mathrm{a}_{\mathrm{lb}}=\dot{\mathrm{Ca}}_{\mathrm{a}_{\mathrm{abs}}}\left(\mathrm{Ca}_{\mathrm{p}}+\mathrm{Ca}_{\mathrm{d}}\right) /\left(\mathrm{Ca}_{\mathrm{p}}{ }^{*}+\mathrm{Ca}_{\mathrm{d}}{ }^{*}\right) \\
& \dot{\mathrm{C}}_{\mathrm{a}_{\mathrm{b}}}=\dot{\mathrm{C}}_{\mathrm{a}_{\mathrm{lb}}}-\dot{\mathrm{C}}_{\mathrm{a}_{\mathrm{ab}}}
\end{aligned}
$$

The subscripts in, out, i, p, d, and abs refer to entry into the test segment, passage out of the test segment, the infusate, fluid recovered from the proximal aspiration site, fluid recovered from the distal aspiration site, and net absorption, respectively. $Q$ refers to volume in $\mathrm{ml} / \mathrm{min}, \mathrm{PEG}$ to concentration of $\mathrm{PEG}$ and $\mathrm{Ca}^{*}$ to concentration of ${ }^{47} \mathrm{Ca}$, each as the fraction of its concentration in the infusate. $\mathrm{Ca}$ refers to concentration of calcium in $\mu \mathrm{moles} / \mathrm{ml}, \dot{\mathrm{C}} \mathrm{a}^{*}$ and $\dot{\mathrm{Ca}}$ to radiocalcium and calcium flux rates, respectively $(\mathrm{ml} / \mathrm{min}$ per $50 \mathrm{~cm}$ and $\mu$ moles $/ \mathrm{min}$ per $50 \mathrm{~cm})$. $\dot{\mathrm{C}} \mathrm{a}_{\mathrm{lb}}$ and $\dot{\mathrm{C}} \mathrm{a}_{\mathrm{bl}}$ are the unidirectional rates of transfer of calcium from lumen to blood and from blood to lumen, respectively ( $\mu \mathrm{moles} / \mathrm{min}$ per $50 \mathrm{~cm}$ ).

Several other parameters used hereafter are calculated as follows: the mean concentration of calcium within the test segment $=\mathbf{C a}_{\mathrm{m}}=\left(\mathbf{C} \mathbf{a}_{\mathrm{p}}+\mathrm{Ca}_{\mathrm{d}}\right) / 2$; water absorbed $=Q_{\mathrm{abs}}$ $=Q_{\text {in }}-Q_{\text {out }} ;$ absorption efficiency $=\dot{\mathrm{C}} \mathrm{a}_{\mathrm{lb}} / \mathrm{Ca}_{\mathrm{m}}$.

Several procedures were carried out to evaluate the validity of the assumption that movement of ${ }^{47} \mathrm{Ca}$ occurred only as part of $\dot{\mathrm{C}} \mathrm{a}_{\mathrm{lb}}$ to any significant degree. First, in several experiments, blood samples were withdrawn during the intestinal perfusion with radioactive calcium. Analyses of these samples showed that the concentration of ${ }^{47} \mathrm{Ca}$ in the plasma always remained below $2 \%$ of that of the solution in the intestinal lumen. Second, in four of the subjects, a special additional set of experiments was performed in which the radioactive calcium was omitted from the intestinal perfusion solution and instead injected intravenously $24-36 \mathrm{hr}$ beforehand. Due to calcium secretion, the concentration of ${ }^{47} \mathrm{Ca}$ in the perfusion solution passing through the test segment generally increased, but this increase never exceeded $10 \%$ of the plasma ${ }^{47} \mathrm{Ca}$ concentration. Thus, secretion of radioactive calcium was less than $0.2 \%$ (calculated from $2 \%$ times $10 \%$, as determined above) of the ${ }^{47} \mathrm{Ca}$ in the test segment. Since in the main experiments the absorption of ${ }^{47} \mathrm{Ca}$ averaged more than $20 \%$ of the average amount passing through the test segment, the assumption of a negligible degree of back flux was confirmed.

Although it is most reasonable that the specific activity within the test segment would decrease exponentially, we have used the conventional simplifying assumption that both the specific activity and the calcium concentration changed in a linear manner within the test segment. Though this linear approximation unquestionably introduces an inaccuracy, its magnitude is small when the specific activity decrease is small, as it was in these studies. For example, if the specific activities of the solution entering and leaving the test segment are $100 \%$ and $70 \%$ respectively, then the linear assumption gives a mean value of $85 \%$ while the exponential assumption gives $83.8 \%$, which for this experiment would not be a significant difference. In all but 9 of the 64 experiments, the values of specific activity at the distal sampling site were above $70 \%$ of the proximal value.

Clinical material. Nine male and one female normal subjects, age 36-62 yr, were studied while ambulatory within the Clinical Research Center of the University of Washington Hospital. Each was healthy, apparently free of metabolic, gastrointestinal, pancreatic, or hepatic diseases, and exhibited no abnormalities of calcium metabolism. Physical activity and diet (including calcium intake) during the $2 \mathrm{yr}$ before study had been ordinary, without unusual exposure to ultraviolet light, and administration of supplemental calcium, vitamin $\mathrm{D}$, or steroid drugs. In each, the following were normal: hematocrit, total and differential leukocyte counts, urinalysis, serum albumin, total globulins, calcium, phosphorus, alkaline phosphatase, bromsulphalein excretion, and chest X-ray. Three diseased subjects, two with celiac-sprue and one with a parathyroid adenoma, were studied.

Infusates. Calcium gluconate to yield calculated final calcium concentrations of $0.62,1.33,2.5$, or $3.97 \mu \mathrm{moles} / \mathrm{ml}$ was added to $1.3 \mathrm{~mm}$ phosphate buffer, $\mathrm{pH} 7.2$, in isotonic saline. Also added to each liter of infusate were 4 or $5 \mu \mathrm{c}$ of radiocalcium- ${ }^{47}$ as $\mathrm{CaCl}_{2}$ and $1.25 \mathrm{~g}$ PEG (Union Carbide Corp., Chemicals Div., molecular weight approximately 4000 ). When used, the concentration of Phenol red was 20 $\mathrm{mg} /$ liter. The calcium gluconate was added to the infusate just before each perfusion to avoid its precipitation as calcium phosphate during storage. In each study, the actual concentration in the solution infused was determined, and these values were employed in the subsequent calculations.

Protocol. Each subject completely consumed a diet containing $700 \mathrm{mg}$ of calcium and $1300 \mathrm{mg}$ of phosphorus/day for at least 1 wk before and throughout the study period. Other sources of calcium were omitted and no vitamin supplements were given. Each subject fasted 12 or more hr before a perfusion study. 
TABLE I

Summary data, Calcium and Water movement, all Experiments

\begin{tabular}{|c|c|c|c|c|c|c|c|c|}
\hline Subject & Experiment & $\mathrm{Ca}_{\mathrm{m}}$ & Qabs & $\dot{C}_{\text {ain }}$ & $\dot{C}_{a} a_{a b}$ & Ćalb & Ċabı & $\dot{\mathrm{C}} \mathrm{alb}_{\mathrm{b}} / \mathrm{Ca}_{\mathrm{m}}$ \\
\hline & & umoles $/ \mathrm{ml}$ & $\mathrm{ml} / \mathrm{min}$ per $50 \mathrm{~cm}$ & $\begin{array}{l}\text { Mmoles } / \text { min } \\
\text { per } 50 \mathrm{~cm}\end{array}$ & mmoles/ & $50 \mathrm{~cm}$ & $\begin{array}{c}\text { mmoles } / \mathrm{min} \\
\text { per } 50 \mathrm{~cm}\end{array}$ & $\underset{\operatorname{per} 50 \mathrm{~cm}}{\mathrm{ml} / \mathrm{min}}$ \\
\hline \multirow[t]{3}{*}{1} & $1 a$ & 1.12 & -1.0 & 10.8 & 3.0 & 3.6 & 0.6 & 3.25 \\
\hline & $1 \mathrm{~b}$ & 3.52 & 2.4 & 29.7 & 6.1 & 7.0 & 0.9 & 2.00 \\
\hline & 2 & 1.07 & 2.7 & 12.5 & 2.2 & 4.1 & 1.9 & 3.79 \\
\hline \multirow[t]{6}{*}{2} & 1 & 0.95 & -0.1 & 7.5 & 1.0 & 1.5 & 0.4 & 1.54 \\
\hline & 2 & 1.10 & -0.4 & 6.5 & 0.9 & 0.9 & 0.0 & 0.82 \\
\hline & $3 a$ & 1.19 & 0.2 & 9.4 & 0.7 & 1.3 & 0.7 & 1.12 \\
\hline & $3 b$ & 3.53 & 0.9 & 26.8 & 2.7 & 3.2 & 0.5 & 0.90 \\
\hline & $4 a$ & 2.05 & 0.1 & 18.9 & 3.5 & 3.5 & 0.0 & 1.70 \\
\hline & $4 b$ & 3.53 & 1.3 & 27.2 & 3.0 & 3.9 & 0.9 & 1.09 \\
\hline Ileal* & $5 a$ & 1.37 & 1.0 & 11.7 & 0.6 & 0.5 & -0.1 & 0.35 \\
\hline Ileal & $5 b$ & 3.22 & -2.3 & 33.0 & -0.6 & 1.6 & 2.2 & 0.50 \\
\hline \multirow[t]{3}{*}{3} & 1 & 3.05 & 1.4 & 27.7 & 3.3 & 3.8 & 0.5 & 1.25 \\
\hline & 2 & 1.07 & 2.7 & 10.0 & 3.4 & 3.2 & -0.2 & 3.02 \\
\hline & 3 & 1.15 & 0.5 & 13.4 & 2.6 & 3.4 & 0.8 & 2.93 \\
\hline \multirow[t]{4}{*}{4} & 1 & 1.20 & 0.1 & 8.4 & 0.3 & 2.2 & 1.9 & 1.85 \\
\hline & $2 a$ & 1.34 & 3.9 & 13.2 & 2.9 & 4.4 & 1.5 & 3.25 \\
\hline & $2 b$ & 3.45 & 3.4 & 37.2 & 7.5 & 9.1 & 1.7 & 2.65 \\
\hline & 3 & 1.23 & 1.4 & 10.4 & 1.3 & 2.9 & 1.6 & 2.36 \\
\hline Ileal & 4 & 1.46 & 0.4 & 8.2 & 0.3 & 0.8 & 0.4 & 0.51 \\
\hline Ileal & 5 & 2.43 & 1.0 & 19.5 & 0.7 & 0.4 & -0.4 & 0.15 \\
\hline Ileal & 6 & 3.84 & 0.4 & 23.2 & 2.4 & 1.5 & -0.9 & 0.39 \\
\hline \multirow[t]{3}{*}{5} & 1 & 1.14 & -0.6 & 11.5 & 2.0 & 2.5 & 0.5 & 2.18 \\
\hline & 2 & 1.92 & 3.8 & 20.0 & 0.8 & 3.8 & 3.0 & 1.99 \\
\hline & 3 & 1.95 & -0.2 & 18.6 & 2.6 & 3.6 & 1.1 & 1.87 \\
\hline \multirow[t]{2}{*}{6} & $1 \mathrm{a}$ & 1.28 & 2.1 & 11.3 & 2.3 & 3.8 & 1.5 & 2.97 \\
\hline & $1 b$ & 3.18 & 1.9 & 31.8 & 8.0 & 8.3 & 0.3 & 2.59 \\
\hline Ileal & $2 a$ & 1.37 & 0.7 & 9.7 & 0.7 & 1.7 & 1.0 & 1.22 \\
\hline Ileal & $2 b$ & 3.83 & 0.8 & 26.6 & 3.3 & 3.9 & 0.6 & 1.03 \\
\hline \multirow[t]{3}{*}{7} & $1 \mathrm{a}$ & 0.51 & 1.2 & 4.9 & 2.3 & 2.0 & -0.3 & 4.00 \\
\hline & $1 b$ & 4.32 & 1.4 & 32.6 & 6.0 & 6.5 & 0.5 & 1.50 \\
\hline & $2 a$ & 0.47 & 3.1 & 5.9 & 2.5 & 2.5 & 0.0 & 5.20 \\
\hline pt & $2 b$ & 0.52 & 2.5 & 4.9 & 1.8 & 2.3 & 0.5 & 4.46 \\
\hline$p$ & $2 c$ & 0.54 & 0.3 & 3.2 & 0.2 & 2.3 & 2.1 & 4.32 \\
\hline \multirow[t]{2}{*}{8} & $1 \mathrm{a}$ & 0.53 & 1.5 & 6.2 & 2.2 & 2.2 & 0.1 & 4.19 \\
\hline & $1 b$ & 0.51 & 1.2 & 5.6 & 2.4 & 2.0 & -0.4 & 4.01 \\
\hline \multirow[t]{2}{*}{$\mathbf{p}$} & $1 c$ & 0.52 & 2.3 & 5.8 & 2.4 & 2.6 & 0.2 & 5.01 \\
\hline & $2 a$ & 0.57 & 2.7 & 7.5 & 2.5 & 3.3 & 0.7 & 5.78 \\
\hline $\mathbf{p}$ & $2 \mathrm{~b}$ & 0.57 & 1.4 & 4.3 & 1.4 & 2.2 & 0.8 & 3.90 \\
\hline $\mathbf{p}$ & $2 c$ & 0.56 & 1.8 & 5.4 & 2.1 & 2.8 & 0.7 & 4.99 \\
\hline 9 & $1 \mathrm{a}$ & 1.48 & 1.8 & 6.5 & 2.6 & 2.5 & -0.1 & 1.71 \\
\hline \multirow[t]{5}{*}{$\mathbf{p}$} & $1 b$ & 1.69 & 2.8 & 7.6 & 3.4 & 3.6 & 0.2 & 2.13 \\
\hline & $2 a$ & 1.37 & 1.2 & 9.0 & 1.8 & 2.2 & 0.4 & 1.59 \\
\hline & $2 b$ & 1.51 & 1.7 & 8.6 & 2.0 & 2.6 & 0.6 & 1.71 \\
\hline & $3 a$ & 1.50 & 3.7 & 9.7 & 3.6 & 4.1 & 0.5 & 2.71 \\
\hline & $3 b$ & 1.44 & 3.2 & 9.6 & 2.8 & 3.3 & 0.5 & 2.28 \\
\hline
\end{tabular}

* Experiments labeled "lleal" are those in which the sampling tubes were placed in the distal small intestine.

$\ddagger$ Experiments labeled " $p$ " indicate those in which parathyroid hormone was injected just before the experimental run. 
TABLE I-Continued

\begin{tabular}{|c|c|c|c|c|c|c|c|c|}
\hline Subject & Experiment & $\mathrm{Ca}_{\mathrm{m}}$ & Qabs & $\dot{C} a_{\text {in }}$ & $\dot{C} a_{a b s}$ & Ċalb & $\dot{C} a b 1$ & $\dot{\mathrm{C}} \mathrm{a}_{\mathrm{lb}} / \mathrm{Ca}_{\mathrm{m}}$ \\
\hline & & Mmoles $/ \mathrm{ml}$ & $\mathrm{ml} / \mathrm{min}$ per $50 \mathrm{~cm}$ & $\begin{array}{c}\text { Amoles } / \min \\
\text { per } 50 \mathrm{~cm}\end{array}$ & \multicolumn{2}{|c|}{ umoles $/ \mathrm{min}$ per $50 \mathrm{~cm}$} & $\underset{\text { per } 50 \mathrm{~cm}}{\text { Mmoles } / \mathrm{min}}$ & $\underset{\operatorname{per}}{m l / m i n} \mathrm{~cm}$ \\
\hline 10 & $1 \mathrm{a}$ & 0.62 & 1.6 & 6.5 & 0.3 & 2.2 & 1.9 & 3.59 \\
\hline \multirow[t]{2}{*}{$\mathrm{p}$} & $1 b$ & 0.56 & 1.6 & 4.1 & 1.1 & 2.5 & 1.3 & 4.35 \\
\hline & $2 a$ & 0.42 & 1.6 & 2.6 & -0.1 & 1.4 & 1.5 & 3.30 \\
\hline \multirow[t]{2}{*}{$\mathbf{p}$} & $2 b$ & 0.44 & 1.7 & $4 . \theta$ & 1.1 & 2.1 & 1.0 & 4.71 \\
\hline & $3 a$ & 1.23 & 1.4 & 8.9 & 3.1 & 3.7 & 0.6 & 2.97 \\
\hline \multirow[t]{3}{*}{$\mathrm{p}$} & $3 b$ & 1.26 & 1.4 & 9.0 & 4.0 & 3.7 & -0.3 & 2.92 \\
\hline & $4 a$ & 1.20 & 1.6 & 9.5 & 2.5 & 4.0 & 1.5 & 3.33 \\
\hline & $4 b$ & 1.17 & 2.3 & 8.0 & 3.9 & 4.2 & 0.3 & 3.58 \\
\hline Ileal & $5 a$ & 1.36 & 1.0 & 8.3 & 1.2 & 1.9 & 0.6 & 1.37 \\
\hline Ileal, p & $5 b$ & 1.39 & 1.4 & 9.8 & 2.2 & 2.0 & -0.2 & 1.42 \\
\hline \multicolumn{9}{|c|}{ Celiac-sprue patients } \\
\hline \multirow[t]{2}{*}{11} & $1 a$ & 1.35 & 0.0 & 9.7 & -0.5 & 1.4 & 1.8 & 1.02 \\
\hline & $1 b$ & 3.45 & -0.9 & 29.0 & 1.7 & 0.5 & -1.2 & 0.15 \\
\hline 12 & 1 & 1.06 & -1.3 & 12.3 & 0.5 & 0.7 & 0.2 & 0.66 \\
\hline \multicolumn{9}{|c|}{ Parathyroid adenoma patient } \\
\hline \multirow[t]{2}{*}{13} & $1 a$ & 1.01 & 1.8 & 12.1 & 4.5 & 5.9 & 1.5 & 5.88 \\
\hline & $1 \mathrm{~b}$ & 2.83 & 1.3 & 28.2 & 9.7 & 10.7 & 1.0 & 3.77 \\
\hline
\end{tabular}

Calcium fluxes were determined at two different depths, the upper and lower small intestine. For studies at the upper level, the tube was positioned fluoroscopically so that the infusion site was at the beginning of the second portion of the duodenum, the proximal collection site in the midduodenum, and the distal collection site in the upper jejunum. To prepare for studies at the lower level, the tube was allowed to migrate until the distal end was at least $325 \mathrm{~cm}$ from the teeth, about $25 \mathrm{~cm}$ proximal to the ileocecal valve (13). Before studies in either position, any excess tube in the stomach was withdrawn, and the tube was taped to the cheek to prevent further migration. Radiographs taken before and after each perfusion study consistently demonstrated that apparent forward migration was slight, usually only $1-2 \mathrm{~cm}$, and always less than $5 \mathrm{~cm}$. Evidence for retrograde migration never was observed.

Patients rested comfortably in bed while solutions at $37^{\circ} \mathrm{C}$ were infused by means of a constant rate pump through the infusion lumen at $9.9 \mathrm{ml} / \mathrm{min}$. At the start of an infusion, each collection lumen was primed once with $10 \mathrm{ml}$ of water. Thereafter, recovery of perfusate was obtained from both proximal and distal collection sites by siphonage. Once relatively copious and regular siphonage was obtained (usually $45 \mathrm{~min}$ ), the experimental collections of four to seven consecutive 15 -min samples were begun. When a second solution was perfused during the same intubation, Phenol red as well as PEG was added to the second infusate. Usually after 10-30 min, the concentration of Phenol red, expressed as a per cent of its concentration in the infusate, rose to become equal to that of PEG. This indicated that the original infusate, which contained no Phenol red, was no longer diluting the second infusate, and collection of the siphonage samples for analysis was begun.

In several experiments, the immediate effect of parathyroid hormone was studied. In these runs, 120-200 U of parathyroid extract (Eli Lilly \& Co.) were injected intravenously at the end of the fourth or fifth $15 \mathrm{~min}$ collection period. Consecutive $15-\mathrm{min}$ collections were then obtained for the next $90-150 \mathrm{~min}$ to allow absorption and secretion of calcium to be compared immediately before and after the hormone injection. To validate biologic potency of the parathyroid extract employed, measurements of the renal. tubular reabsorption of phosphate were compared with control values, using urine samples collected continuously during the experiment.

Analytical methods. After measuring volume and $\mathrm{pH}$ at the bedside, the samples were centrifuged immediately to remove mucus and debris ${ }^{1}$ and then refrigerated until further analyzed (within $72 \mathrm{hr}$ ). It was determined experimentally that the measurements of ${ }^{47} \mathrm{Ca}$, stable calcium, PEG, and Phenol red were not altered by the preliminary centrifugation or by such storage. Chemical and radioactivity measurements were made in duplicate upon volumetric aliquots of intestinal siphonage and serum.

Calcium was measured by titration against Versene, using an automatic titrating and recording system (15). PEG was determined according to the method of Hyden (16) and Phenol red by the method of Allen (17) as modified by Schedl and Clifton (18) to avoid interference from the presence of bile. It was determined that $P$ henol red and PEG may be used simultaneously and each measured without interference from the other.

Calcium- ${ }^{47}$ was counted by means of an automatic gamma spectrometer, adjusted so that only gamma radiation with energy greater than $0.80 \mathrm{mev}$ would be detected. Thus, the

\footnotetext{
1 The amount of sediment was always negligible, and in none of the frequent checks was there a significant amount of ${ }^{47} \mathrm{Ca}$ in the centrifuged sediment. ${ }^{\circ 0} \mathrm{Ca}$ concentration of the uncentrifuged specimens was the same as for the corresponding supernates. The conditions for our studies were quite different than for the work reported by Schedl, Osbaldiston, and Mills (14), in which appreciable precipitation of calcium was observed.
} 
$1.31 \mathrm{mev}$ gamma radiation of ${ }^{47} \mathrm{Ca}$ was detected, but not the less energetic radiation of ${ }^{47} \mathrm{Sc}$. It was determined experimentally that when a sample of ${ }^{~}{ }^{77} \mathrm{Ca}$ plus its radioactive decay product ${ }^{47} \mathrm{Sc}$ was treated so that the ${ }^{47} \mathrm{Sc}$ was completely absorbed on glass, there was no reduction of the counting rate, thereby indicating that ${ }^{47} \mathrm{Sc}$ made no contribution to the activity from the original sample. Sufficient counts were obtained from all samples so that the probable counting error was less than $2 \%$, except for the measurements of serum radioactivity, in which the probable error was calculated to be less than $3 \%$.

\section{RESULTS}

Each experiment consisted of from four to seven sampling periods of $15 \mathrm{~min}$ each. The values for the individual periods were averaged so that the data of Table I represent total continuous collection times of 60-105 min for each experiment. Experiments denoted by different numbers (e.g. 1, 2, 3) were performed on different days. Experiments denoted by the same number (e.g., $1 \mathrm{a}, 1 \mathrm{~b}, 1 \mathrm{c})$ were separate experiments performed in sequence on the same day. Experiments in which the sampling tubes were placed in the distal small intestine are labeled "ileal"; in all other experiments, the test segment was in the proximal (duodenojejunal) intestinal region. A " $p$ " indicates an experiment in which parathyroid hormone was injected just before the experimental run. A negative absorption value in Table I indicates net secretion.

The mean and sD of the numerical $\mathrm{pH}$ values measured on all samples were $6.37 \pm 0.65$ at the duodenojejunal sampling site and $6.49 \pm 0.52$ at the ileal sampling site.

Effect of calcium concentration on calcium fluxes in the normal duodenum and upper jejunum. Results ob-

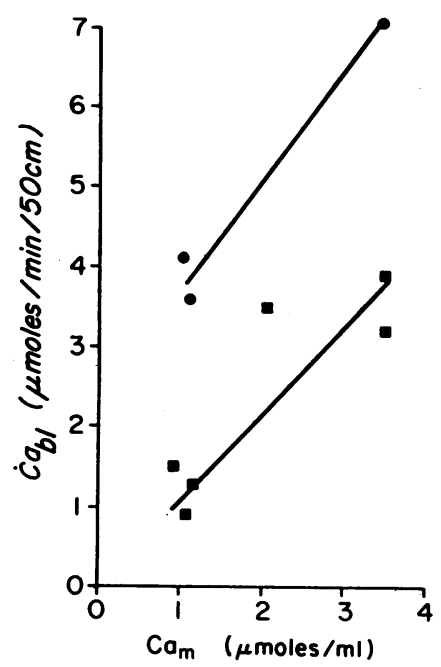

Figure 1 Plot of flux of calcium, lumen to blood, versus average calcium concentration in the lumen for the upper (duodenojejunal) test segment, subjects $1(\bullet)$ and $2(\boldsymbol{\theta})$.

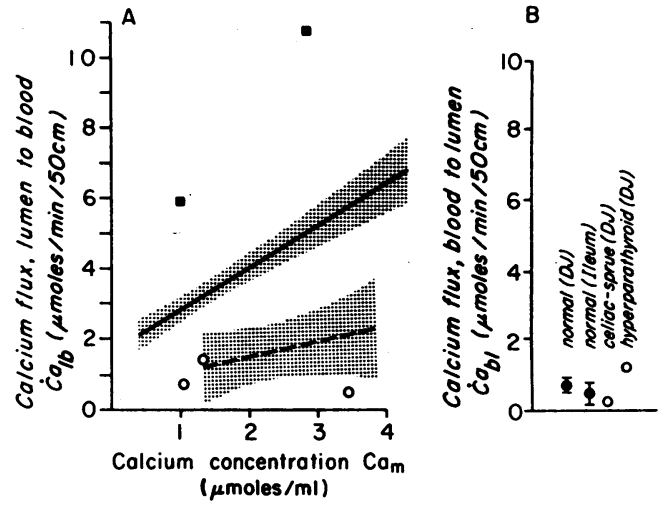

Figure 2 A. The linear regression equations relating calcium flux from lumen to blood with average concentration of calcium in the lumen for all duodenojejunal studies of normal subjects (upper line -) and for all ileal studies of normal subjects (lower line - - ). The shaded areas represent the $95 \%$ confidence intervals for these two lines. The individual duodenojejunal studies of two patients with sprue $(O)$ and one with a parathyroid adenoma ( $\square$ ) also are shown. B. Plots of calcium flux, blood to lumen, for the four groups of experiments indicated in A. Note that flux is not plotted as a function of intraluminal concentration, since $\mathrm{Ca}_{\mathrm{b} 1}$ did not appear to depend upon $\mathrm{Ca}_{\mathrm{m}}$.

tained for all normal subjects when the test segment was the duodenojejunum showed the same pattern; namely, $\dot{C}_{1 b}$ rose with increasing intraluminal calcium concentration while $\dot{C} a_{b 1}$ showed little relation to the concentration of calcium in the lumen. The relationship between $\dot{C}_{a} b$ and luminal calcium concentration is illustrated by plotting all studies in two representative subjects in Fig. 1, and by the regression lines plotted for all studies of all subjects in Fig. 2. Positive correlation of $\dot{C} a_{1 b}$ with $\mathrm{Cam}$ was found to be significant $(P<0.001)$.

The generally lower magnitude and lack of any comparable dependence of $\dot{C} a_{b 1}$ upon the intraluminal concentration of calcium is illustrated also in Fig. 3. Analyses of these points gives a mean value of $\dot{C} a_{b 1}$ of $0.76 \mu$ moles $/ 1 \mathrm{~min}$ per $50 \mathrm{~cm}$ of intestine. (The five slightly negative values of $\dot{C} a_{\text {b }}$ must be in error, since by

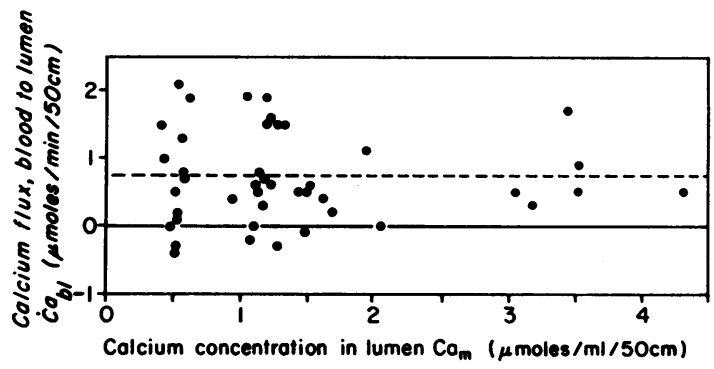

FIGURE 3 Plot of flux, blood to lumen ( $\dot{C} a_{b_{1}}$ ), from the upper. (duodenojejunal) test segment for all normal subjects. The dashed line represents the mean value. 


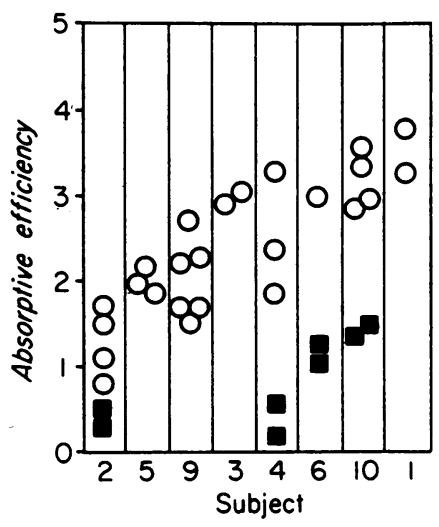

FIGURE 4 Summary graph of absorptive efficiency $\left(\dot{\mathrm{C}} \mathrm{a}_{1 \mathrm{~b}} /\right.$ $\left.\mathrm{Ca} a_{m}\right)$ for all experiments on normal subjects in which $\mathrm{Ca}_{m}$ was between 0.95 and $1.69 \mu \mathrm{moles} / \mathrm{ml}$. Open circles are results from the duodenojejunal segments and solid squares are results from the ileal segments.

definition, unidirectional transport can be only positive or zero. Their magnitude provides some indication of the errors characteristic of these experimental techniques.)

Ileal calcium transport in normal subjects. The values obtained for ileal calcium movement are compared with those of duodenojejunum in Fig. 2. The magnitude of the flux $\dot{C}_{a_{1 b}}$ is much smaller than that in the more proximal intestine. $\dot{C}_{a_{1 b}}$ is not significantly correlated with $\mathrm{Cam}_{\mathrm{m}}(P>0.2)$, but the slope of this regression line cannot be defined accurately from the small number of observations made; conceivably a correlation might be evident had many more additional studies been conducted.

Influence of water movement and parathyroid hormone. There was no significant correlation between either the magnitude or the direction of water movement and the rate of calcium movement. Parathyroid hormone injected just before the experimental run had no significant effect upon calcium transport.

Effect of celiac-sprue and hyperparathyroidism. Two patients with celiac-sprue and one with a parathyroid adenoma were similarly studied. Although too few in number to come to definitive conclusions about the effect of these conditions upon calcium movement, the results obtained, illustrated in Fig. 2, are strongly suggestive. Both patients with celiac-sprue showed a marked reduction of $\dot{C}_{a}$, with values approximately equal to $\dot{C}_{a b 1}$ at both intestinal levels studied, while the patient with a parathyroid adenoma had a marked elevation.

\section{DISCUSSION}

Because of the known importance of the duodenum for calcium absorption in lower mammals, as much of the duodenum as possible was included in the upper intestinal segment perfused in these studies. Nevertheless, by so placing the infusion site in the proximal part of the second portion of the duodenum, a possible uncontrollable error was introduced into certain of the data, via potential duodenogastric regurgitation of fluid which had already entered the study segment. Thorough mixing of infusate with digestive juices within the 10 $\mathrm{cm}$ mixing segment is an inherent assumption for our calculations. Because of the high placement of the in fusion site in the duodenum, pancreatic and biliary fluid might occasionally enter sufficiently distal to introduce more than the usual degree of mixing imperfection. However, it is believed that such errors were actually of minor importance because of the relative consistency of the data, its reproducibility in the same subject on different occasions, and the relative constancy of siphonage retrieve from the proximal collecting site. Bile staining occurred only rarely among the siphonage samples analyzed.

We found that calcium was absorbed effectively from infusates in which the concentration of calcium ranged between one-third and three times the concentration of ionized calcium in normal plasma. These results are consistent with those of others $(1,3,4,19,20)$ which demonstrate that calcium can be absorbed from the intestinal lumen against a concentration gradient. Since ion activities were not measured, we are unable to determine from our data that this was due to active transport; however, others have shown that active transport for calcium occurs $(1,3,4,21)$.

The characteristics of normal absorption of calcium in humans, described in our results, can be compared with intestinal absorption in lower animals. Previous studies of absorption using isolated intestinal loops and other methods have demonstrated (a) a similar dependence of $\dot{C} a_{1 b}$ on intraluminal concentrations, (b) evidence consistent with an active transport mechanism which tends towards saturation when the intraluminal concentration is high, $(c)$ much greater absorption proximally than distally, and $(d)$ only a very slow C $\dot{C}_{\text {ab }}$ $(1,3,4,19,21,22)$.

Our data tend to support the concept that the efficiency of absorption is relatively constant when the same subject is repeatedly studied at different times, but that there is considerable variability from person to person. To illustrate this phenomenon, we have plotted in Fig. 4 the absorptive efficiency $\left(\dot{\mathrm{C}} \mathrm{a}_{1 \mathrm{~b}} / \mathrm{Ca}_{\mathrm{m}}\right)$ for all studies on normal subjects in which $\mathrm{Cam}_{\mathrm{m}}$ was between 0.95 and $1.69 \mu \mathrm{moles} / \mathrm{ml}$. It is evident that the studies of any given patient show consistency even though carried out at different times over a period of weeks. Such relatively constant individual absorptive function compared to the considerable difference between individuals possibly could be the reflection of an adaptive mechanism. But, if so, it must be a relatively slow one, as all subjects were studied under similar conditions of activity 
and controlled diet, which they had taken for several weeks before the first experimental observations were conducted. It seems much more probable that these results reflect inherent differences between individuals in their ability to absorb calcium. This pattern has been less apparent from balance measurements and isotopic studies of absorption conducted when subjects were not fasting. Such methods, which measure absorption of calcium from mixed solid food, are influenced not only by intestinal absorptive capacity, but also by factors such as intestinal motility and pancreatic and biliary function. These others factors, which importantly determine the physical state of calcium in the small intestinal lumen and its period of contact with intestinal mucosa, could together obscure the effect of intestinal absorptive ability per se. When the effect of these other factors is minimized by measuring absorption of a solution of calcium salt administered to fasted persons, a similar pattern of reproducibility in the same person but large variation between different subjects has been found $(6,23$, 24).

No general conclusions can be drawn from the studies of a single patient with parathyroid adenoma. However, the findings in this case, of a markedly increased $\dot{C}_{1 b}$ are consistent with numerous reports of hyperabsorption of calcium by patients with hyperparathyroidism $(6,24)$. In contrast to the accelerated calcium absorption in chronic hyperparathyroidism, no change was observed during the $2 \mathrm{hr}$ after an intravenous injection of parathyroid extract sufficient to reduce markedly the reabsorption of phosphate in the renal tubules. Thus, it appears that the action of parathyroid hormone on calcium absorption is evident only after some lapse of time, as might be expected if there is an intermediary step such as transcription and protein synthesis before the calcemic actions of parathyroid hormone are expressed $(25,26)$.

The few studies of celiac-sprue showed markedly reduced $\dot{C} a_{1 b}$ from the upper intestinal segment, but $\dot{C} a_{b 1}$ at the upper site and both fluxes at the lower site gave values similar to those of normals (Fig. 2). Thus, the main defect observed in this limited set of data was a reduction of the proximal absorptive transport function for calcium.

\section{ACKNOWLEDGMENTS}

Appreciation is expressed to Dr. John F. Fordtran for detailed advice on design and construction of perfusion tubing, and also to Dr. James A Clifton for similar suggestions.

These studies were supported in part by research grants from the National Institute of Arthritis and Metabolic Diseases of the U. S. Public Health Service (AM 06657 and AM 09096) and from Pharmacia Laboratories. A portion of this work was conducted through the Clinical Research Center facility of the University of Washington, supported by the National Institutes of Health (Grant FR-37).

\section{REFERENCES}

1. Wasserman, R. H., F. A. Kallfelz, and C. L. Comar. 1961. Active transport of calcium by rat duodenum in vivo. Science (Washington). 133: 883.

2. Cramer, C. F. 1963. Quantitative studies on the absorption and excretion of calcium from Thiry-Vella intestinal loops in the dog. In The Transfer of Calcium and Strontium Across Biological Membranes. R. H. Wasserman, editor. Academic Press Inc., New York. 75.

3. Krawitt, E. L., and H. P. Schedl. 1968. In vivo calcium transport by rat small intestine. Amer. J. Physiol. 214: 232.

4. Schachter, D., and S. M. Rosen. 1959. Active transport of $\mathrm{Ca}^{45}$ by the small intestine and its dependence on vitamin D. Amer. J. Physiol. 196: 357.

5. Heaney, R. P., and T. G. Skillman. 1964. Secretion and excretion of calcium by the human gastrointestinal tract. J. Lab. Clin. Med. 64: 29.

6. Avioli, L. V., J. E. McDonald, R. A. Singer, and P. H. Henneman. 1965. A new oral isotopic test of calcium absorption. J. Clin. Invest. 44: 128.

7. DeGrazia, J. A., P. Ivanovich, H. Fellows, and C. Rich. 1965. A double isotope method for measurement of intestinal absorption of calcium in man. J. Lab. Clin. Med. 66: 822.

8. Lutwak, L., and J. R. Shapiro. 1964. Calcium absorption in man: Based on large volume liquid scintillation counter studies. Science (Washington). 144: 1155.

9. Wensel, R. H., C. Rich, and W. Volwiler. 1963. Calcium absorption in man measured by intestinal intubation. Clin. Res. 11: 102. (Abstr.)

10. Wensel, R. H., C. Rich, and W. Volwiler. 1964. Studies of calcium absorption and endogenous secretion in normal man. Gastroenterology. 46: 768. (Abstr.)

11. Cooper, H., R. Levitan, J. S. Fordtran, and F. J. Ingelfinger. 1966. A method for studying absorption of water and solute from the human small intestine. Gastroenterology. 50: 1 .

12. Fordtran, J. S. 1966. Marker perfusion techniques for measuring intestinal absorption in man. Gastroenterology. 51: 1089.

13. Hirsch, J., E. H. Ahrens, Jr., and D. H. Blankenhorn. 1956. Measurement of the human intestinal length in vivo and some causes of variation. Gastroenterology. 31: 274.

14. Schedl, H. P., G. W. Osbaldiston, and I. H. Mills. 1968. Absorption, secretion, and precipitation of calcium in the small intestine of the dog. Amer. J. Physiol. 214: 814.

15. Jones, J. D., and W. F. McGuckin. 1964. Complexometric titration of calcium and magnesium by a semiautomated procedure. Clin. Chem. 10: 767.

16. Hydén, S. 1955. A turbidometric method for the determination of higher polyethylene glycols in biological materials. Kungl. Lantbrukshögskolans Ann. 22: 139.

17. Allen, W. M. 1950. A simple method for analyzing complicated absorption curves, of use in the colorimetric determination of urinary steroids. J. Clin. Endocrinol. Metab. 10: 71 .

18. Schedl, H. P., and J. A. Clifton. 1961. Small intestinal absorption of steroids. Gastroenterology. 41 : 491. 
19. Schachter, D., E. B. Dowdle, and H. Schenker. 1960. Active transport of calcium by the small intestine of the rat. Amer. J. Physiol. 198: 263.

20. Cramer, C. F., and J. Dueck. 1962. In vivo transport of calcium from healed Thiry-Vella fistulas in dogs. Amer. J. Physiol. 202: 161.

21. Schachter, D., D. V. Kimberg, and H. Schenker. 1961. Active transport of calcium by intestine: action and bioassay of vitamin D. Amer. J. Physiol. 200: 1263.

22. Wasserman, R. H., editor. 1963. The Transfer of Calcium and Strontium Across Biological Membranes. Academic Press Inc., New York.
23. Kinney, V. R., W. N. Tauxe, and W. H. Dearing. 1965. Isotopic tracer studies of intestinal calcium absorption. J. Lab. Clin. Med. 66: 187.

24. DeGrazia, J. A., and C. Rich. 1964. Studies of intestinal absorption of calcium ${ }^{\text {ss }}$ in man. Metab. (Clin. Exp.). 13: 650 .

25. Rasmussen, H., C. Arnaud, and C. Hawker. 1964. Actinomycin D and the response to parathyroid hormone. Science (Washington). 144: 1019.

26. Zull, J. E., E. Czarnowska-Misztal, and H. F. DeLuca. 1965. Actinomycin D inhibition of vitamin D action. Science (Washington). 149: 182. 